\title{
Passive Smoke Exposure
}

National Cancer Institute

\section{Source}

National Cancer Institute. Passive Smoke Exposure. NCI Thesaurus. Code C17140.

Exposure to tobacco smoke products among individuals who do not smoke. This can result from sharing space with a smoker or from placental transfer from mother to fetus. 